\title{
MAJOR ACCIDENT PLANNING-THE ROLE OF THE QUEEN ELIZABETH MILITARY HOSPITAL
}

\author{
CAPT B ROBERTSON, LRCP, MRCS, RAMC* \\ Queen Elizabeth Military Hospital, Woolwich
}

\begin{abstract}
SUMMARY: In the event of a major accident occurring in South East London the role of the Queen Elizabeth Military Hospital in support of the civilian medical authorities is described. The equipment prepared for use by the Mobile Medical Team that would be despatched to the scene is also described. The paper illustrates an area where the Army Medical Services can make a valuable contribution to the civilian emergency services provided proper planning and integration takes place. It also serves to familiarise Army Medical Service personnel with the terminology used in civilian major accident planning.
\end{abstract}

\section{Introduction}

“. . . Britain can expect an incident of disaster proportions to accur on average at a rate of two per year and herein lies one of the main problems: persuading everyone to accept that a disaster may happen in their area and to devote sufficient time, effort, and resources to the plan."

Leading article (1975). British Medical Journal 3, 723.

The Queen Elizabeth Military Hospital, as was one of its predecessors, the Royal Herbert Hospital, is situated in an area of London that has had its share of disaster situations, and where potential hazards can be readily identified. Rail accidents have occurred at Lewisham in 1957 (85 killed, 138 injured), Hither Green in 1967 (49 killed, 102 injured) and Eltham Well Hall in 1972 (five killed, 126 injured). As a result of these along with the terrorist bombing of a Woolwich public house in 1974 (one killed, 33 injured) the Army has been incorporated for some years in the Regional and Area Health Authority plans to cope with such disasters in the future.

With the opening of the Queen Elizabeth Military Hospital a complete revision of the hospital major accident plan and equipment has been undertaken in order to take into account newer concepts of disaster management and also to integrate our preparations with those of the London Ambulance Service and the local Area Health Authority organisation. This paper describes the role of the Queen Elizabeth Military Hospital in a major accident situation and also describes the equipment prepared for use in such an eventuality.

There are many definitions of what constitutes a major accident but the currently accepted definition is an incident which because of the number and severity of live casualties requires special arrangements for its management ${ }^{1}$. When a major accident occurs a hospital is "designated" for the incident by

" Now Maj B Robertson, RAMC(V), 331 ATC, RAMC(V). 
the ambulance service involved as are two supporting hospitals. It is also accepted practice that the Site Medical Officer and any Mobile Medical Teams required should in the first instance be provided by the designated hospital.

The Site Medical Officer is in overall medical administrative charge of the incident, in liaison with the emergency services, and is not a member of a mobile team. His role is to make the policy decisions necessary to cope with the incident in liaison with the Ambulance Incident Officer. These include locating the Casualty Clearing Station where the mobile Medical Team or Teams will work and to which casualties will be brought by the search and rescue teams of the emergency services. Consideration must also be given by the Site Medical Officer and Ambulance Incident Officer to the assessment and distribution of the casualty load, taking due note of any particular problems such as toxic or radiation hazards. The effective utilisation of volunteer first aid and medical workers will also come into their brief.

The composition of mobile medical teams vary considerably from hospital to hospital and can vary from a single doctor and nurse to a surgeon, anaesthetist plus a variable number of nurses. It is possible that a well staffed hospital can provide a number of different teams to perform different functions as described by Finch and Nancekievill ${ }^{2}$.

There has been much debate about the value of mobile medical teams at the scene of a major accident because they often arrive too late to be of value and they: often pass the bulk of the casualties going into the hospital they have just left. This accepted procedure of the designed hospital providing the Site Medical Officer and Mobile Medical Teams is self defeating in that it depletes the hospital of medical and nursing staff at a time when they could be receiving the largest number of casualties and depending on the time of day may themselves be short of staff ${ }^{3} 45 \mathrm{~b}$.

There is however a role for a properly equipped and trained team at the scene particularly if the situation is going to take time to clear, if there are many trapped casualties or if there are long distances for casualties to be transported 289 . Regrettably it is the training for this situation that is difficult to achieve because with the notable exception of Belfast, the average hospital sees very few disaster situations and the rapid turnover of junior staff means that any expertise gained is rapidly dispersed ${ }^{6}{ }^{10}$. It is with this in mind that the General Practitioner Immediate Care Schemes around the country are being incorporated into major accident plans. With their increasing experience of on-site co-operation with the emergency services this is undoubtedly beneficial ${ }_{311} 1213$. It might well be that in future planning, the Site Medical Officer could be a general practitioner particularly if he has had accident experience and he may well be more rapidly on scene than one drawn from the designated hospital.

\section{The role of the Queen Elizabeth Military Hospital}

In the Greenwich, Bexley, Bromley and Orpington areas of South East London the Queen Elizabeth Military Hospital has taken over the site responsi- 
bility from the hospitals likely to be designated for any incident. This then means that the Army Medical Services will provide the Site Medical Officer and if needed two Mobile Medical Teams at the request of the designated hospital (Figure 1). In the initial response to the incident one mobile team will

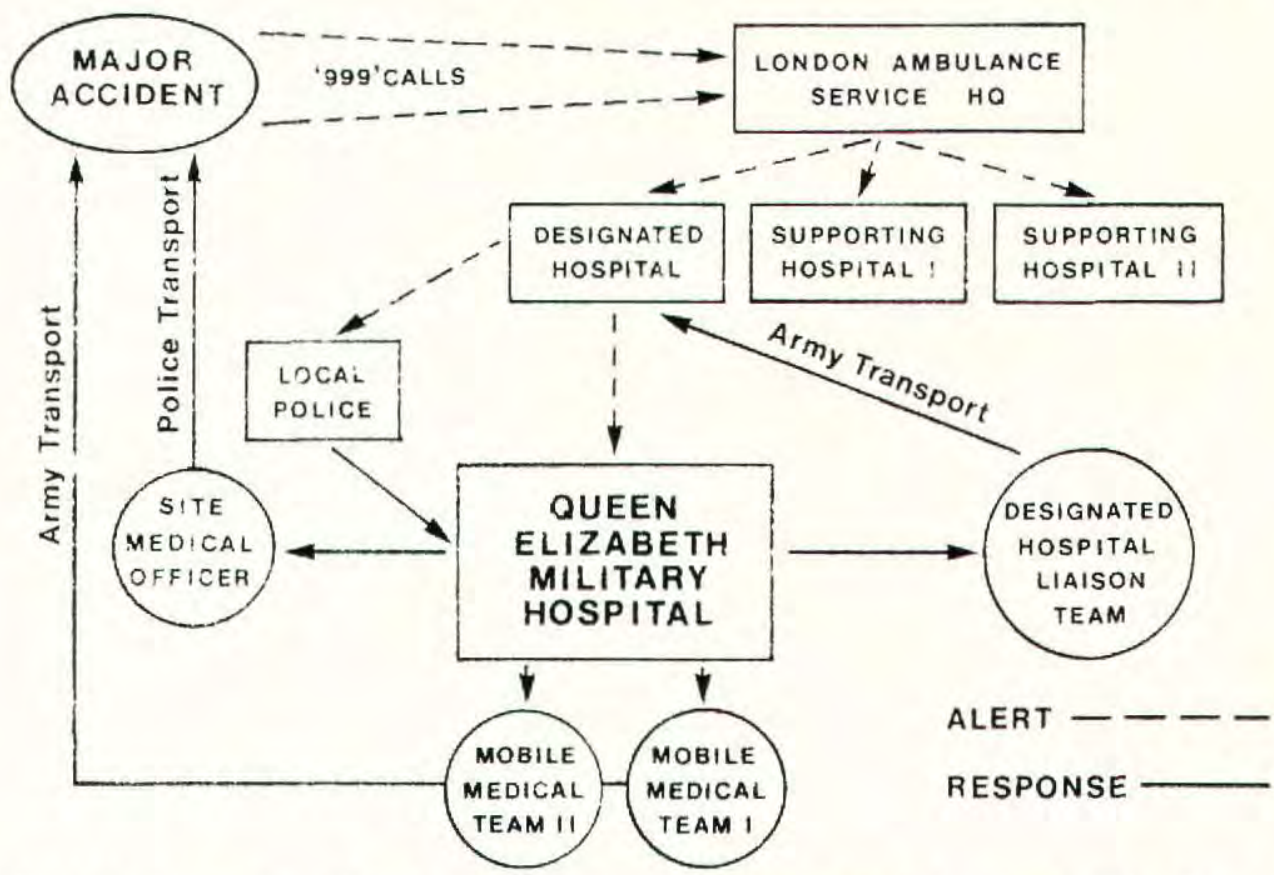

Fig. 1. Major accident lines of Communication and the Initial Response of the Queen Elizabeth Military Hospital.

be despatched immediately and consists of a surgeon and anaesthetist, four trained nurses, two medical assistants and two operating theatre technicians. They will carry the equipment detailed elsewhere in this paper. A second mobile team with identical staffing and equipment is stood-by and can be called to the scene if required by the Site Medical Officer or Ambulance Incident Officer once the extent of the incident has been assessed.

These mobile elements provided by the Army Medical Services have now relieved both designated and supporting hospitals of the need to provide teams at least in the initial confused stages of the incident and they can concentrate on receiving casualties. It is not intended in this paper to describe the hospital major accident plan which is based on the use of action cards for duty personnel ${ }^{7}$, but it revolves round the need for a rapid response using the staff on-duty at the time of the incident, as this hospital will only receive casualties as a secondary role.

As the Queen Elizabeth Military Hospital is acting as an 'extension' of the designated hospital a liaison team of a medical officer and a clerk is despatched 
to the designated hospital in the initial response phase. Their role is to see what further help can be offered by the Army Medical Services as the extent of the incident becomes clearer and also to monitor any Service casualties and to offer transfer facilities.

\section{Transport}

Transport for the Site Medical Officer is provided by the Metropolitan Police and for the Designated Hospital Liaison Team from Army resources. With regard to the transport for the medical team it is impracticable to follow the usual procedure of collection by a London Ambulance Service vehicle because of the size of the team. However, if available at the time of the incident it is intended to utilise one of the Hospital's Bedford ambulance coaches (Figure 2).

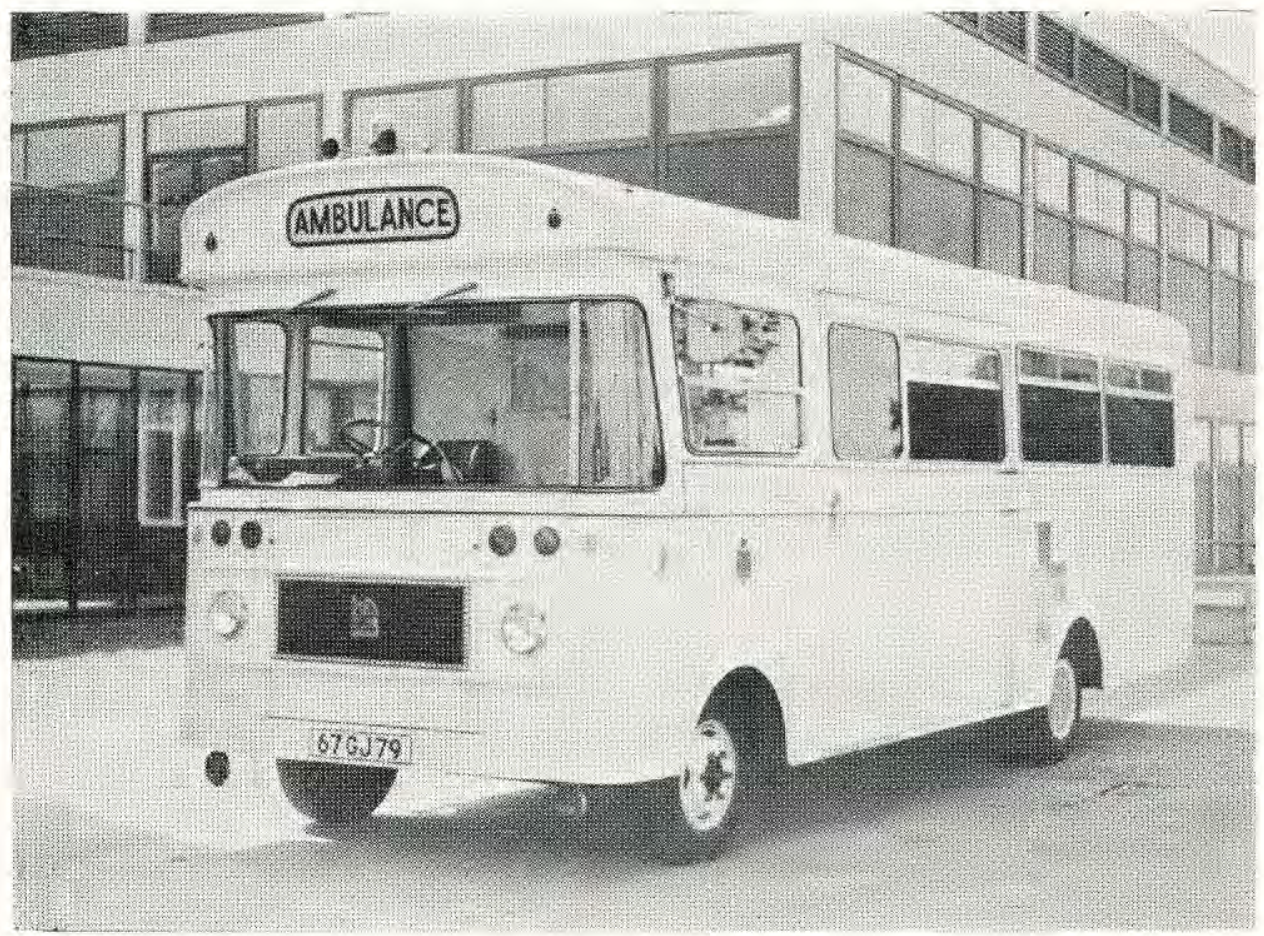

Fig. 2. Army Medical Services Bedford ambulance coach containing 14 seats, a centre mounted ambulance trolley and fitted with a hydraulic tail lift.

These are of ideal size, with audible and visual warning devices and will provide a focal point from which the Mobile Medical Team can work when on-site. In an ideal situation it would be located alongside the London Ambulance Service Emergency Control vehicle which forms the Ambulance and Mobile Medical Control Point for the incident. In the event of one of these vehicles not being available other Service vehicles would be used. 


\section{Equipment}

Major accident planning is often an unpopular and time consuming occupation with, in the case of equipment, little interdisciplinary discussion and the inevitable difficulties and reluctance to have capital equipment lying idle for maybe years at a time. Many proposals have been made regarding the equipment needed by a mobile team at the scene of a major accident and it is difficult to reach agreement on one standard scale of equipment as all doctors have their individual preferences ${ }^{214}$. This is reflected in the fact that several attempts have been made over the years to standardise such a set of major accident equipment for all military hospitals but unfortunately without lasting success. It is perhaps more realistic to scale each set of equipment to the particular circumstances in which it might be employed, as has been done in this case.

The two Queen Elizabeth Military Hospital Mobile Medical Teams would only be deployed in support of the London Ambulance Service and therefore fully equipped ambulances would be at the scene as would be the London Ambulance Service reserves of dressings, first aid and rescue equipment. Portable suction, Entonox and oxygen are available on all London accident ambulances with further reserves available on a divisional basis therefore these bulky items can be dropped from the mobile team equipment. The medical officer in charge of the Mobile Medical Team has only to ask the Ambulance Incident Officer for these items when he is setting up his Casualty Clearing Station in the appointed place and they will be provided. This therefore means that the Mobile Medical Team must carry essential resuscitation equipment and surgical equipment that may be necessary for the release of the inextricably trapped casualty but not large quantities of dressings.

There have been differing views over the ways in which major accident equipment should be carried varying from individually packed items in the pockets of protective clothing through personal satchels for every team member to assorted cases and boxes. Containers varying from cricket bags to wicker panniers have been seen in various hospitals.

The Queen Elizabeth Military Hospital equipment has been packed in four easily portable lightweight fibreboard boxes, measuring 620 × 420 × $230 \mathrm{~mm}$ and available from Army sources. Each serves a particular function namely 'Box 1-Airway/Drugs', 'Box 2-Intravenous Infusion', 'Box 3-Surgical' and 'Box 4-Dressings'. (Figure 3). The full contents list is included as an appendix to this paper.

Box 1 contains those items associated with maintenance of the airway and also the drugs that are considered necessary. As elsewhere in the equipment care has been taken to pack together items that would be needed together in the heat and confusion of the incident. All items necessary for intubation are held in an Ambu intubation wallet (Figure 4) with reserves of endotracheal tubes and airways elsewhere in the box. This wallet could also be of considerable use in other Service field situations to avoid mislaying items. All the drugs are stored together in one dispensary sealed box dated with the nearest run-out-date thus removing the need for repeated counting of 


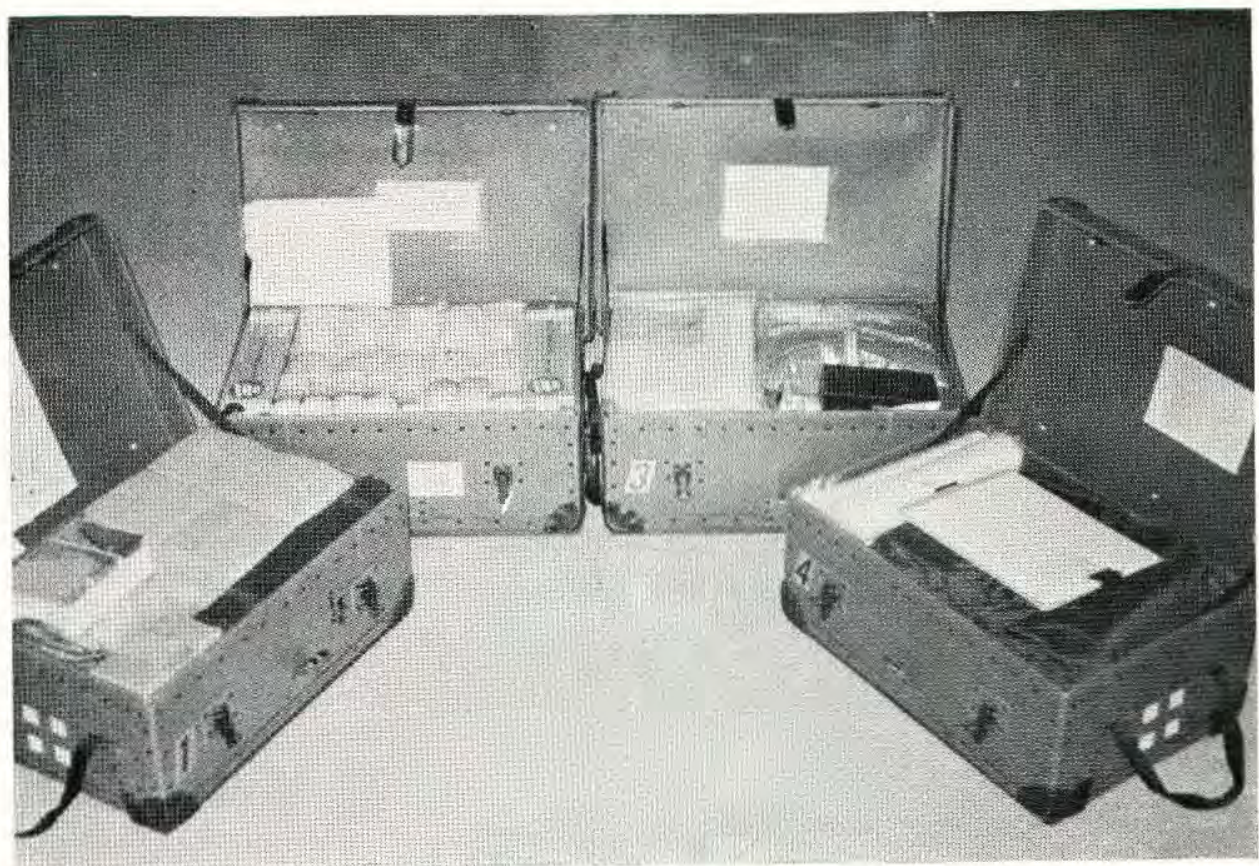

Fig. 3. The major accident equipment.

ampoules. In Box 2 each intravenous giving set has been opened and repacked as recommended by $S$ nook $^{15}$ with an intravenous cannula, mediswab, crossmatch bottle and form so that an intravenous infusion can be set up with the minimum of effort. In Box 3, which contains all the surgical equipment including amputation and cut-down sets, those items required to insert a chest drain are similarly packed together. It will be noted from the contents list that large plastic bags are included as they can serve as groundsheet, rubbish bag, or even be used for dismembered remains. Large water resistant laminated paper drapes and a box of disposable gloves are also included.

The role of a medical officer to certify death on site is also important and therefore necessary diagnostic instruments should be carried. The certification of a dead victim may allow more rapid extrication of a trapped live casualty ${ }^{2}$.

It is a common error when designing a set of major accident equipment to only include one of such items as Resusci bags or sphygnomanometers. Despite the fact that such items involve capital expenditure it is essential, for example, when a casualty has been intubated at the scene and requires ventilation while being transported to hospital, there must be another Resusci bag available for the next patient that may need it. The equipment described here contains four Resusci bags for immediate use; as these leave the scene replacements can be requested through the Ambulance Equipment Officer as the London Ambulance Service uses the same Laerdal Resusci Bag and therefore endotracheal tube connectors are interchangeable. 


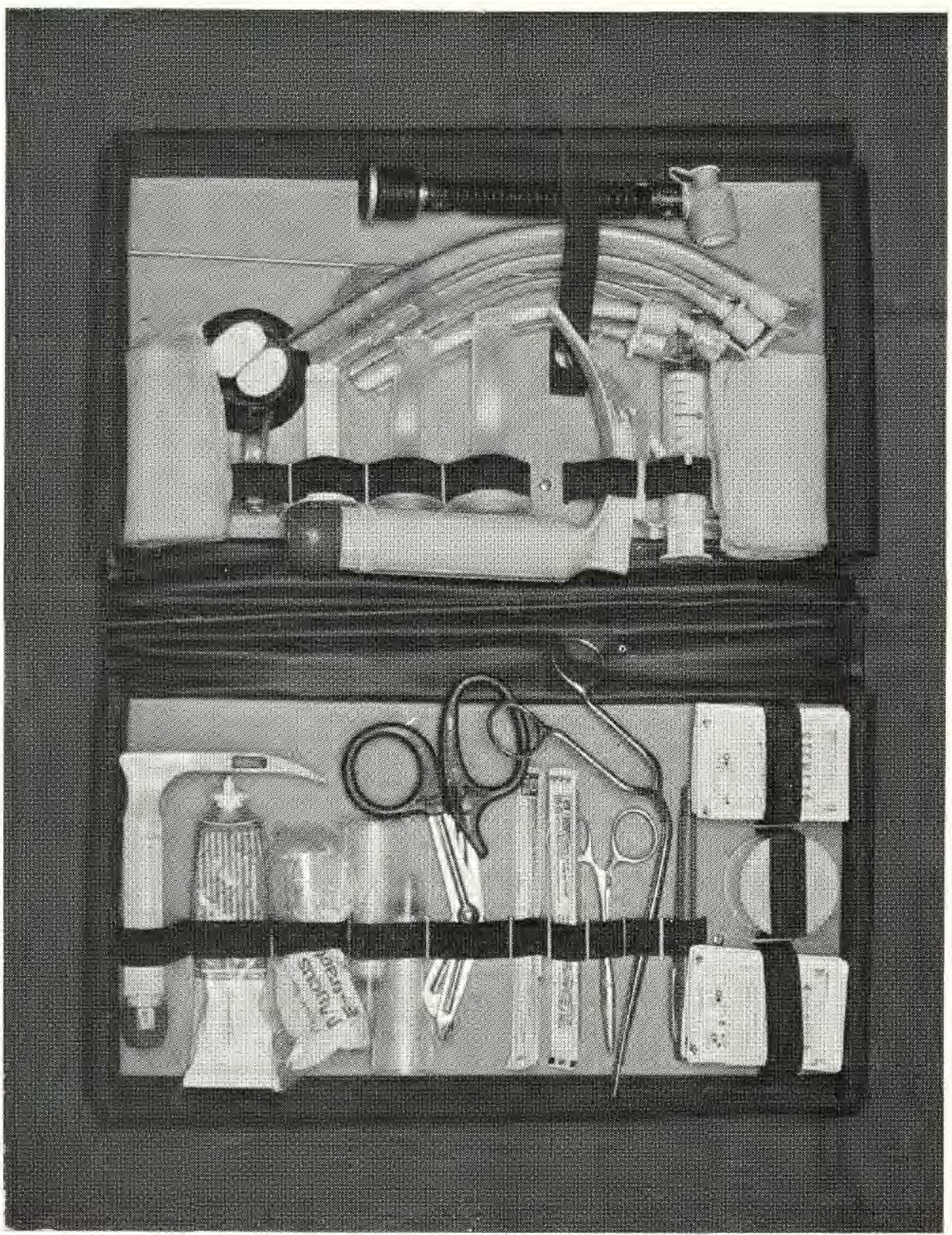

Fig. 4. The Ambu intubation wallet containing all the items necessary for intubation.

The provision of portable anaesthetic facilities in the major accident situation has been discussed by various authors ${ }^{26} 1 \%$ is. As yet no portable anaesthetic machine is included in the equipment described here as the basic items in Box 1 for the maintenance of the airway and drugs such as Ketamine are considered to be the first line requirement. The provision of a portable anaesthetic machine as a reserve item is, however, being considered. 
The decision to pack this equipment in boxes was based on the accepted concept of a Mobile Medical Team functioning as a Casualty Clearing Station at a fixed point on the disaster ground. In the event of work being necessary on a particular casualty in the wreckage of the incident then individual staff are detached. With this in mind, Box 4 contains two Immediate Aid Satchels containing, in addition to basic first aid equipment, a litre of Hartmann's Solution and the necessary items to establish an intravenous infusion. Working out of boxes of this type is also a familiar concept for Army Medical Officers and Medical Assistants hence their adoption for this equipment.

Identification tabards for each team member are provided, as is protective headwear but protective clothing is at present under review along the lines suggested by Savage ${ }^{19}$.

\section{Casualty labelling}

Casualty labelling at the scene of a major accident is another area of difficulty, as standardisation of labels and priority classifications is almost impossible to achieve. DHSS Circular $\mathrm{HC}(77) 1$ calls for a uniform casualty labelling system with which everyone is conversant but different ambulance services use different casualty labels and different hospitals use different priority $\operatorname{codes}^{128}$. London Ambulance Service casualty labels are included in this hospital's equipment so that some uniformity exists in the area of likely operation. The Army Forms F.MED 25 and 26 traditionally included in military hospital major accident equipments are too complicated for use by non-military personnel. In a large incident there could be as many as four or five mobile medical teams, which if using different casualty labels will increasingly confuse the receiving hospitals. A major accident casualty label needs to be simple, only needing space for personnel details if known, injuries apparent, drugs and intravenous fluids administered.

This paper has described the preparations made by one Military Hospital to cope with a major accident situation. It is well accepted that views on both methods and equipment may need to be varied from hospital to hospital be they civil or military. It does, however, illustrate an area in which a valuable contribution can be made by the Army Medical Service to the local community provided careful integration and planning is undertaken.

\section{Appendix \\ QUEEN ELIZABETH MILITARY HOSPITAL-MAJOR ACCIDENT PLAN MOBILE MEDICAL TEAM EQUIPMENT \\ BOX 1-AIRWAY/DRUGS}

Resusci-bags (Laerdal) complete with airways

Intubation Wallet (Ambu) containing:Laryngoscope Penlon adult

Laryngoscope Penlon child

Endotracheal Tubes-

Cuffed Portex, $10.0 \mathrm{~mm}, 8.0 \mathrm{~mm}, 6.0$

$\mathrm{mm}$

Syringe $20 \mathrm{ml}$

1 Syringe $5 \mathrm{ml}$

Artery Forceps 5 inch

McGill Introducing Forceps-adult

1 set

Scissors Bandage Universal 
Uncuffed Portex $5.0 \mathrm{~mm}, 4.0 \mathrm{~mm} 1$ set Catheter Mount $15 \mathrm{~mm} / 22 \mathrm{~mm}$ BOC 1 Introducers Malleable KY Jelly

Airways Oropharyngeal-Size 0.1231 tube

IV Cannula Butterfly $23 \mathrm{G} / 25 \mathrm{G} \quad 2$ sets

IV Cannula Abbocath $16 \mathrm{G} / 18 \mathrm{G} \quad 1$ set
Bandage 1 inch WOW

Zinc Oxide Plaster 1 inch

Gauze Swabs (Unsterile)

Mediswabs

Mucous Extractor

Felt Tip Pen
2
1 roll
12
10
1
1

Sphgmomanometer Aneroid

Scissors Bandage Universal

Scissors General Surgical 5 inch

Artery Forceps

Mouth Gag Ackland

Syringes $20 \mathrm{ml}$

Syringes $10 \mathrm{ml}$

Syringes $2 \mathrm{ml}$

Needles $21 G \times 1 \frac{1}{2}$ inches
Zinc Oxide Plaster 1 inch

1 roll

1 Bandage 1 inch WOW

$\begin{array}{rlr}1 & \text { Zinc Oxide Plaster 1 inch } & 1 \text { roll } \\ 1 & \text { Bandage 1 inch Wow } & 6 \\ 2 \text { pair } & \text { Oropharyngeal Airways Sizes 0.1.2 } & 5 \text { sets } \\ 2 \text { pair } & \text { Oropharyngeal Airways Size 3 } & 10 \\ 2 \text { pair } & \text { Endotracheal Tubes- } & \\ 1 & \text { Cuffed Portex Size 8.0 mm } & 6 \\ 10 & \text { Uncuffed Portex Size } 5.0 \mathrm{~mm} & 6 \\ 10 & \text { Gauze Swabs (Unsterile) } & 1 \text { packet } \\ 40 & \text { Laminated Paper Drapes (36 x 36 inches) } 4 \\ 75 & \text { Plastic Bag (Large) } & 4\end{array}$

DRUGS (in separate sealed container)

Morphine $15 \mathrm{mg} / \mathrm{ml}$ Ampoule $\quad 40$ ampoules

Lignocaine Hydrochloride 1 per cent

6 multi-dose vials

Ketamine $50 \mathrm{mg} / \mathrm{ml}$

6 multi-dose vials

Scoline $100 \mathrm{mg}$

Valium $10 \mathrm{mg}$

10 ampoules

Sterile Water 5

20 ampoules

Atropine $0.6 \mathrm{mg}$

10 ampoules

\section{BOX 2-INTRAVENOUS INFUSION}

Hartmanns Solution 1 litre (Polyfusor) Dextran-70 (with bottle hangers)

Airways for glass bottles

Giving Sets (A100) each box additionally containing IV Cannula-1, Cross-match Bottle-1, F.Med 12A-1, Mediswabs-3
15 Crepe Bandage $10.0 \mathrm{~cm}$

3 Zinc Oxide Plaster 1 inch

3 Micropore 1 inch

Scissors Bandage Universal

Spare IV Cannulae (Assorted)

18 (1) 
No. 12 Standard Dressings

Scissors General Surgical

Scissors Bandage Universal

Artery Forceps 5 inches

Airways Oropharyngeal Size 3

Mucous Extractor

Dispos-a-Gloves Medium

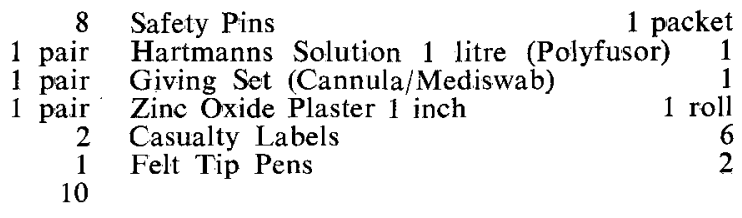

The boxes used are H4/6545/NO 3029 container fibreboard No. II A5, without dividers, size $620 \times 420 \times 230 \mathrm{~mm}$.

\section{Acknowledgements}

I should like to thank Brig R H Freeman, CBE, FRCS, Late RAMC, Commanding Officer, Queen Elizabeth Military Hospital, for permission to publish and also to Mr D E Bengeyfield, Divisional Officer, London Ambulance Service, for much helpful advice.

\section{REFERENCES}

1. Department of Health and Social Security, Health Service Arrangements for dealing with Major Accidents, $\mathrm{HC}(77) 1$.

2. FINCH, $P$ and NANCEKIEVILL, $D$ (1975). British Journal of Hospital Medicine 13, 601

3. Miller, P J (1971). Injury 2, 168.

4. WILSON, R I (1974). Injury 5, 228.

5. TUCKER, T and LeTTIN, A (1975). British Medical Journal 3, 287.

6. Moles, T M (1977). British Journal of Anaesthesia 49, 643.

7. Savage, P E A (1972). British Medical Journal 3, 42.

8. Richardson, J W (1975). Ed. Disaster Planning, J Wright, Bristol.

9. NAGGAM, L (1976). Injury 7, 279.

10. RUtherFord, 'W H (1973). Injury 4, 189.

11. RUTHERFORD, W H (1975). British Medical Journal 1, 443.

12. WINCH, R D et al (1976). Injury 7, 288.

13. London, P S (1978). British Journal of Hospital Medicine 20, 169.

14. GABRIEL, R W (1977). Anaesthesia 32, 179.

15. SNooK, R (1974). Medical Aid at Accidents. Update Publications, London.

16. RedDen, $\mathrm{J}$ F and Little $\mathrm{K}$ (1973). British Medical Journal 1, 788.

17. FrYer, M E and Boulton, T B (1977). Anaesthesia 32, 189.

18. SANDERS, C D (1977). British Journal of Clinical Equipment 2, 5.

19. SAvage, P E A (1976). Injury 7, 286. 